\title{
Pensamento decolonial e INTERCUlTURALIDADE Na AMÉrica LATINA: DESAFIOS PARA A EDUCAÇÃO
}

A proposta do dossiê incluído neste número de $E C C O S$, nasce de iniciativa conjunta de grupos de pesquisa de várias instituiçóes universitárias [GRUPEFE, Uninove; NESEF, Uniplac; GRUPEI, Unilassale], unidos em parceria em torno de uma atividade investigativa e militante comum sobre a emergência do pensamento decolonial na América Latina. Os referidos grupos têm se dedicado ao estudo e ao debate do pensamento latino-americano, do que tem resultado análises e reflexôes de cunho filosófico-educacional que, de um lado, consubstanciam críticas às modalidades hegemônicas do pensamento colonial na cultura e nos modelos epistemológicos em que se fundamentam os sistemas educativos do continente americano e, de outro, avançam posiçóes nativas buscando implementar a criatividade, a originalidade e a autonomia dos modos de pensar e ser locais/regionais. Partem da premissa de que a superação da situação de alienação cultural e epistêmica em que vivem as sociedades colonizadas é condição sine qua non para a emancipação de suas populaçôes. Isso exige a crítica à dominação não só política e econômica, mas também à dominação cultural, causadora do silenciamento das racionalidades locais mediante um processo de epistemicídio que inibiu o pleno exercício de sua capacidade de criação em todas as dimensões da produção simbólica. O processo colonizador, ao lado de sua condição hegemônica nos âmbitos econômico e político, impôs às sociedades conquistadas a sua própria expressão cultural, desqualificando, sufocando, reprimindo e até mesmo destruindo as manifestaçôes das culturas locais/regionais. Foi o que ocorreu com a colonização na América Latina, na África e na Ásia ao longo dos últimos séculos.

Agora, ao final do primeiro milênio gregoriano, as populaçóes locais vêm se conscientizando e tomando decisóes no sentido de se libertarem igualmente desse monoculturalismo e de afirmarem suas próprias criaçóes culturais. Os povos colonizados dão-se conta da alienação de sua 
condição e se póem em atitude de questionamento, reivindicando seu direito à existência e à voz. Redinamizam suas experiências de agir, de pensar e de sentir e cobram seu direito de ser, nesse passo afrontando e dessacralizando o paradigma hegemônico que o sufoca. Essa lenta e capilar tomada de consciência da necessidade de afirmaçáo das culturas locais e, no seio delas, da expressão filosófica nativa, vem levando pensadores latino-americanos, africanos e asiáticos à conclusão de que a filosofia, em geral, e a filosofia da educação, em particular, entre nós, devem ser praticadas sob uma perspectiva etnofilosófica, vale dizer, precisa levar em conta seu enraizamento, assumindo-se como manifestação de uma cultura de singular configuração, posicionando-se contra a hegemonia impositiva da pretensa universalidade da filosofia "eurocidentocêntrica", ainda que sem romper seu contato, intercâmbio e diálogo com as expressóes das logosferas de outras culturas, inclusive as do Ocidente. Em matéria filosófica, trata-se de recusar tanto o monoculturalismo quanto o multiculturalismo, para se relacionar de uma forma intercultural crítica. Interculturalidade a ser entendida como uma postura que vai além da aceitação tolerante e da convivência passiva entre culturas diferentes, que avança, conscientemente, para uma interação intencionada, a partir da identidade de cada uma, sem isolar-se sobre si mesmas.

Para tanto, vem procedendo a uma crítica ao pressuposto da superioridade da civilização ocidental-capitalista, reconhecendo e afirmando sua capacidade epistêmica para a criação e manifestação de suas culturas específicas. Configura-se, então, um quadro de múltiplas culturas que coexistem e se afirmam em condiçóes de igualdade, pleiteando-se uma atitude de diálogo e respeito recíproco. Só sob essa perspectiva intercultural pode ganhar legitimidade em meio às injunçóes de um processo globalizador no qual todas as culturas possam se fazer presentes e atuantes com seus valores próprios, repudiando a hierarquização epistemológica que, derivada de um pretenso sucesso econômico, invade e inibe o plano da criação simbólica latino-americana.

É igualmente sob essa perspectiva que se impõe à educação a tarefa de promover a formação dos homens e mulheres latino-americanos que enfrentarão os novos desafios de um contexto descolonizado. E à Filosofia da Educação se imputa a responsabilidade de contribuir para o esclarecimento do sentido das práticas históricas mediadoras de suas existências, 
com a 'ciência' de que o processo intercultural envolve, simultaneamente, as dimensôes epistêmica, ética e política, sendo, consequentemente, vinculado à prática educativa.

Buscou-se, no presente dossiê, compor um painel que fosse representativo dos diferentes movimentos culturais dos quais emergem tentativas e se configuram experiências de perfil descolonizante, dando conta de iniciativas e esforços de movimentos sociais e de instituiçôes educativas de povos afro-latinos. Assim, constam relatos de práticas de cunho intercultural entre as comunidades latino-americanas, de experiências envolvendo investimentos educativos de populaçôes indígenas, iniciativas pedagógicas que ensaiam caminhos descolonizantes, atividades culturais relacionadas à herança cultural africana e debate sobre a própria representação da africanidade.

A expectativa é de que essas breves abordagens desses diferentes aspectos que manifestam as contradiçóes da vida humana em Nuestra América, ainda marcada pelas sequelas da colonização, possam despertar o interesse dos leitores e subsidiar a continuidade e o aprofundamento de sua discussão, consolidando cada vez mais os laços que devem unir cultura, educação e emancipação dos seres humanos em todos os quadrantes do planeta.

O primeiro artigo do Dossiê, de João Alberto Steffen Munsberg, é uma reflexão sobre a interculturalidade como estratégia de aproximação entre pesquisadores brasileiros e hispano-americanos na perspectiva da descolonização. É um estudo de cunho bibliográfico exploratório, com reflexôes a partir de aportes teóricos de pensadores do Grupo Modernidade/ Colonialidade e afins e tem por finalidade pensar sobre as dificuldades de aproximaçáo e diálogo entre países e povos latino-americanos numa perspectiva de promoção do diálogo intercultural entre pesquisadores brasileiros e hispano-americanos como passo importante para a decolonialidade.

José Licínio Backes, apresenta os resultados de um trabalho empírico realizado com e por estudantes indígenas de mestrado, em texto intitulado A construção de pedagogias decoloniais nos curriculos das escolas indígenas. Os dados foram obtidos por intermédio de entrevistas semiestruturadas com estudantes pertencentes às etnias Terena, Guarani e Tuyuca, por meio da análise de suas dissertaçôes. $\mathrm{O}$ autor conclui que a construção dos currículos e das pedagogias decoloniais se baseia, sobretudo, na forte vinculação 
com as comunidades e na perspectiva de que a diferença entre conhecimentos não significa hierarquização e desqualificação, mas complementaridade entre saberes diferentes.

O terceiro artigo, de Jorge Alejandro Santos, Leonel Piovezana e Luci Teresinha Marchiori dos Santos Bernardi, Colonialidad y descolonización en la educación latinoamericana: el caso de las licenciaturas interculturales indigenas con el Pueblo Kaingang, apresenta uma experiência de implementação da educação intercultural e prática decolonial na formação de professores indígenas do povo Kaingang no âmbito da Licenciatura Intercultural Indígena da Universidade Comunitária da Região de Chapecó (Unochapecó). A partir das propostas freirianas, os autores sugerem orientaçôes pedagógicas que visem uma releitura da perspectiva intercultural para implementar uma educação libertadora na formação de professores Kaingang.

Pensar a África em sala de aula: ensino, conhecimento logopático e africanidades no filme Beasts of no nation, de Humberto Perinelli Neto e Alexandre Cristiano Baldacin Junior, é o quarto artigo. Nele se apresenta uma análise do filme Beasts of no nation, com a preocupaçáo de gerar sua apropriação pedagógica para o desenvolvimento de uma prática educativa voltada para a Educação das Relaçóes Étnico-Raciais, mais especificamente o Ensino de História e Culturas Africanas. Os autores consideram que a interpretação promovida indica que esse longa-metragem resulta interessante para a reflexão sobre conceitos como etnia, nação, fronteiras, Estado, permitindo compreender a realidade dos países africanos.

Ana Maria Netto Machado traz, no quinto texto, uma perturbadora experiência de descolonização subjetiva. Sob o título Do desprezo à valorização do "portunhol": testemunho de uma perturbadora experiência de descolonização subjetiva, o trabalho se inscreve na perspectiva teórica decolonial e pretende contribuir com o aspecto menos debatido na literatura pertinente: estratégias de desprendimento da retórica da modernidade nas suas dimensões epistêmica e subjetiva.

A educação infantil e as práticas pedagógicas descolonizadoras: possibilidades interculturais, de Tarcia Regina da Silva e Adelaide Alves Dias, resultado de pesquisa empírica realizada num Centro Municipal de Educaçáo Infantil (CMEI) da cidade de Recife, analisa as práticas pedagógicas das professoras da Educação Infantil, comprometidas com a valorização da 
diversidade étnico-racial. As autoras, partem do pressuposto de que uma educaçáo pautada em/para os Direitos Humanos que incorpore, desde a Educação Infantil, o direito à diferença na perspectiva intercultural contribui para que as crianças negras construam positivamente sua identidade. Os resultados da pesquisa, de caráter qualitativo, revelam que as práticas desenvolvidas no CMEI partem do princípio da incorporaçáo do outro como verdadeiramente outro e, nesse sentido, o respeito à diferença constitui um dos princípios fundamentais das práticas pedagógicas.

O último artigo do Dossiê, de Albert Alan de Sousa Cordeiro e Sônia Maria da Silva Araújo, tem o sugestivo título jogo capoeira: uma pedagogia decolonial?, no qual toma como objeto de análise o trabalho desenvolvido por um professor de capoeira. Os autores discutem como as práticas educativas, presentes no jogo da capoeira, podem configurar processos formativos decoloniais e emancipatórios em oposição aos processos formativos fundamentados na matriz colonial do poder, do saber e do corpo. Os resultados da pesquisa mostram que o jogo da capoeira, fundamentado na cosmogonia africana, produz processos educativos decoloniais, por problematizar o racismo, as diferenças culturais e as desigualdades sociais.

À margem do Dossiê são apresentados 10 artigos, de caráter generalista, que aportam aos mais diversos temas e sob as mais diversas abordagens em educação.

O primeiro, de Daniela Couto Guerreiro Casanova e Miguel Henrique Russo, Crenças de eficácia de gestores escolares e as metas do IDESP, analisa as relações entre as crenças de eficácia dos gestores escolares e o cumprimento das metas do IDESP das escolas estaduais de Sáo Paulo por eles administradas. A pesquisa mostrou que a crença de auto-eficácia para aspectos instrucionais foi a variável que mais contribuiu para explicar o cumprimento da meta do indicador estadual paulista. Quer dizer, o cumprimento das metas foi realizado devido ao envolvimento dos gestores com os aspectos de ensino e aprendizagem.

$\mathrm{O}$ segundo artigo, $A$ atividade experimental como estrutura para o ensino de Ciências no CECINE nos anos de 1960 e 1970, de Kênio Erithon Cavalcante Lima e Francimar Martins Teixeira, estudo de caráter qualitativo com o recurso a entrevistas e análise documental, teve por objetivo caracterizar o ensino e as estratégias que incorporavam curricularmente experimentos científicos realizados no Centro de Ensino de Ciências do 
Nordeste naquelas décadas, para as intervençôes nos cursos de atualização e de formação aos professores das Ciências Naturais nas regiôes Norte e Nordeste do Brasil. Nessa época, as estratégias pedagógicas buscavam disseminar uma nova proposta de ensino, baseada nos currículos estadunidenses, tomando como referencial as atividades práticas experimentais. Todavia, o objetivo era disseminar e popularizar a ciência na região.

O estudo sobre $A$ interseccionalidade nas politicas de açóes afirmativas como medida de democratização da educação superior, de Daniela Auad e Ana Luisa Alves Cordeiro, teve por finalidade analisar, a partir de dados de pesquisa empírica e documental, alguns dos fatores que interferem na permanência na universidade de mulheres negras cotistas lésbicas e mulheres negras cotistas bissexuais, assim como refletir sobre o enfrentamento às violências que as afetam física, material e psicologicamente rumo ao acesso a bens materiais e simbólicos na universidade e em outras esferas sociais. $\mathrm{O}$ artigo apresentado pretende ser uma contribuição ao processo de democratização profunda da educação superior pela promoçâo da igualdade, equidade e respeito pelas diferenças na educação superior.

Crise ambiental, consumo e artefatos culturais: provocaçóes ao tempo contemporâneo, de Paula Corrêa Henning, Virgínia Tavares Vieira e Clarissa Corrêa Henning, constitui o quarto artigo. Numa época em que o Brasil registra um atraso considerável em relação aos países mais desenvolvidos, no que diz respeito à educação ambiental e preservação do meio ambiente, o estudo constitui uma reflexão e chamada de atenção para os diferentes e contraditórios discursos midiáticos sobre crise ambiental e apelo ao consumo. Os autores consideram que a mídia coloca em operação uma relação de poder, ao fabricar verdades, produzir sentidos e constituir sujeitos.

O quinto artigo, Reflexóes sobre o PROCAMPO - programa de apoio à formação superior em licenciatura em educação do campo, de Ramofly Bicalho, resultado de pesquisas realizadas em educação do campo, na estreita articulação com os movimentos sociais, numa perspectiva histórica e emancipatória, teve por objetivo compreender o Programa de Apoio à Formação Superior em Licenciatura em Educação do Campo, enquanto política pública específica de educação para as áreas rurais oriunda das mobilizaçóes dos movimentos sociais. Os resultados mostram que o Programa contribui para formação político-pedagógica dos educadores 
nas escolas do campo, respeitando-se os valores da solidariedade e da ética presentes na luta pela terra.

No texto $O$ ensino médio no Brasil: universalização do acesso e condiçôes de trabalho, seu autor, Gilvan Luiz Machado Costa, tem como objetivo compreender os limites e as perspectivas à universalização do acesso e às condiçôes de trabalho dos professores no Ensino Médio. A discussão foi realizada a partir dos indicadores educacionais arrolados à qualidade social, com destaque à Taxa de Frequência Líquida e o Esforço Docente, e nas metas do Plano Nacional de Educação 2014-2024. O estudo evidencia os desafios que ainda persistem e afetam o trabalho do professor do Ensino Médio naqueles aspectos, em busca da qualidade desse nível de ensino e da transformação da docência numa profissão socialmente atraente.

O sétimo artigo, Concepções de professores sobre Educação Inclusiva no ensino superior privado, de Mauricio Resende Rodovalho, Geraldo Eustáquio Moreira e Djiby Mané, constitui um estudo das concepçóes dos professores de uma instituição de Ensino Superior particular do interior do Estado de Goiás sobre a inclusão de alunos com necessidades educacionais especiais, nesse movimento postulando a necessidade de formação de professores para a inclusão. Apesar de o estudo incidir sobre um grupo de professores de uma determinada instituição, os autores consideram que as concepçôes de outras instituições de ensino particular são similares aos resultados obtidos na pesquisa realizada.

Sob o título Política de Institucionalização de Polos de Apoio Presencial da Universidade Aberta do Brasil, Tânia Barbosa Martins discute os significados administrativos, pedagógicos e organizacionais atribuídos à institucionalização dos polos, com a finalidade de expansão e interiorização do ensino superior. A autora trabalha analiticamente o conceito de 'institucionalização', considerando as políticas públicas para a Educação a Distância e o Sistema Universidade Aberta do Brasil. A partir de uma pesquisa qualitativa, conclui que há uma noção restritiva do conceito de institucionalização, atrelada a aspectos pedagógicos, administrativos e organizacionais dessa modalidade, que desconsidera ou menospreza as próprias políticas públicas e educacionais.

O penúltimo artigo, de Luciana Rodrigues Ferreira e Vera Lucia Jacob Chaves, é uma reflexão e análise sobre a pós-graduação no Brasil que interpela a proposta de expansão de doutores no novo Plano Nacional de 
Educação, tendo como referência a meta 14. A partir de um estudo exploratório de caráter qualitativo, as autoras concluem que o Brasil deve aprimorar os mecanismos de fomento à pós-graduação para que possa ampliar o número de doutores titulados, visto que, em 2014, os índices ainda demonstravam a existência de cerca de 7,6 doutores por 100.000 habitantes, sendo necessário quintuplicar esse número para o atendimento da meta.

Finalmente, o artigo Trabalho e formação politica dos professores da Educação Básica, de Itacir Carlos Valmorbida e Maurício Roberto da Silva, tem como objetivo a apresentação e a reflexão sobre alguns elementos teórico-práticos que caracterizam a formação política dos professores da rede pública estadual do município de Chapecó (SC). Os autores concluem, ainda que provisoriamente, que é necessário investir numa formação política permanente dos professores de natureza crítico-superadora, centrada na consciência de classe e nas lutas coletivas, e que tenha como cerne ontológico, epistemológico e político-pedagógico a unidade inseparável entre teoria e prática.

Como habitualmente, o número que se apresenta aos leitores é constituído por uma seção de resenhas críticas.

Dadas as temáticas abordadas no presente número, de enorme atualidade e importância acadêmica, consideramos tratar-se de subsídios teóricos e empíricos que poderão contribuir para discussôes alargadas que, por sua vez, possam ser geradoras de alteraçôes profundas na educação brasileira.

\author{
Ana Maria Netto Machado \\ António Joaquim Severino \\ Eduardo Santos \\ Manuel Tavares
}

